PERSPECTIVE

\title{
Evidence-Based Care for People with Chronic Fatigue Syndrome and Myalgic Encephalomyelitis
}

\author{
Michael Sharpe, $M D^{7}$, Trudie Chalder, $P h D^{2} \odot$, and Peter D White, $M D^{3}$ \\ ${ }^{1}$ Psychological Medicine Research, Department of Psychiatry, Warneford Hospital, University of Oxford, Oxford OX3 7JX, UK; ${ }^{2}$ Department of Psychological \\ Medicine, Institute of Psychiatry, Psychology \& Neuroscience, King's College London, 16, De Crespigny Park, London SE5 8AF, UK; ${ }^{3}$ Wolfson Institute \\ of Population Health, St Bartholomew's and The London School of Medicine and Dentistry, Queen Mary University of London, London, UK.
}

Chronic fatigue syndrome (CFS), sometimes referred to as myalgic encephalomyelitis (ME) and often as CFS/ME, is an illness characterized by disabling fatigue and other symptoms, typically worsened by activity. The main evidencebased treatments are rehabilitative in nature and include specific types of cognitive behavior therapy (CBT) and graded exercise therapy (GET). In this article, we briefly review the evidence for their safety and effectiveness and propose that much of the controversy about them arises from misunderstandings about their nature and delivery. In particular, we emphasize that successful rehabilitation from CFS/ME does not indicate that the illness is not real. We recommend that rehabilitative treatment always be preceded by a thorough clinical assessment and delivered by appropriately trained therapists working in close collaboration with the patient. We conclude that properly applied rehabilitative treatments offer the best hope of safely improving fatigue and function for patients with CFS/ME. However, we also recognize the need for more research into the treatment of this neglected condition, especially for those most severely disabled by it.

Keywords Chronic fatigue syndrome - Myalgic encephalomyelitis .

Management · Cognitive behavior · Therapy · Graded exercise therapy

J Gen Intern Med 37(2):449-52

DOI: $10.1007 / \mathrm{s} 11606-021-07188-4$

(C) Society of General Internal Medicine 2021

\section{THE ILLNESS}

Chronic fatigue syndrome (CFS) is a disabling and chronic illness that is characterized by fatigue and other symptoms that are typically exacerbated by exertion (a phenomenon often referred to as post-exertional malaise or PEM) and that are not better explained by an alternative diagnosis. ${ }^{1-3}$ These symptoms are also ascribed to a condition referred to as myalgic encephalomyelitis (ME). ${ }^{1,2,4}$ Whilst some view CFS and ME as distinct illnesses, others believe that they

This article has not been presented previously.

Received August 7, 2020

Accepted October 1, 2021

Published online November 17, 2021 are essentially the same condition and refer to CFS/ME. ${ }^{4}$, ${ }^{5}$ No specific etiology for this condition has yet been established. ${ }^{1,4}$ Whilst all agree that there is a great need for better care of people with CFS/ME, the nature of that care has been much debated. ${ }^{6}$ In this narrative review, we describe rehabilitative treatments and the evidence for such treatments.

\section{MANAGEMENT OF CFS/ME}

Once a thorough assessment of the patient is complete and alternative diagnoses have been excluded, ${ }^{5,7,8}$ the physician is tasked with deciding which treatment the patient with a diagnosis of CFS/ME should be offered? The most researched approaches are the rehabilitative therapies of cognitive behavior therapy (CBT) and graded exercise therapy (GET). ${ }^{9-12}$ These are non-pharmacological approaches that aim to relieve the symptoms and help the patient return to their desired activities.

In CBT, a therapist works collaboratively with the patient to review the way they understand and cope with their symptoms. ${ }^{13}$ It is based on the observation that patients with $\mathrm{CFS} / \mathrm{ME}$ often reduce their activity as a way of coping. This approach is an understandable consequence of the experience that activity leads to an increase in symptoms. As a consequence, they may become profoundly inactive, or get trapped in cycles of rest and activity. CBT aims to help the patient to stabilize and regularize their patterns of activity, rest and sleep, and then try out very gradual and consistent supervised increases in activity, whilst testing out their concerns that greater activity necessarily produces a persistent increase in symptoms. Together with this change in activity, patients are helped to address any social and emotional obstacles to a return to normal activities, using strategies such as problem-solving. ${ }^{13}$

In graded exercise therapy (GET), a therapist also works collaboratively with the patient to first stabilize activity and then to gradually increase it. ${ }^{13}$ Incremental increases in the time spent physically active are carefully and mutually negotiated between patient and therapist. Target heart rate ranges are set when necessary in order to avoid overexertion, and increments in activity are informed by the patient's symptomatic response to 
it. The aim is to achieve $30 \mathrm{~min}$ of light exercise (such as walking) five times a week. Once this level of activity is attained, gradual increases in the intensity of exercise can be considered, depending on the patient's desire and ability to do so. ${ }^{13}$

Whilst the rehabilitative approaches of CBT and GET were developed separately, they have many similarities. For those seeking information on how to deliver these therapies, the manuals for both therapists and patients that were used in a trial that found them to be safe and effective, are freely available on line. ${ }^{13}$

\section{SHOULD YOU RECOMMEND CBT AND GET TO YOUR PATIENTS?}

So, should you recommend CBT or GET to your patients with CFS/ME? We suggest that you should as there are many randomized trials indicating the safety and efficacy of these treatments. ${ }^{9-12}$ However, some commentators suggest that you should not and have disputed the evidence from the trials. $^{6,15-18}$ The dispute has focussed on the largest trial of these treatments done to date, the PACE trial. ${ }^{14}$ PACE was a four-arm trial that recruited over 600 patients. It compared specialist medical care (SMC) alone, with SMC supplemented by one of three therapies. The therapies evaluated in this way were the rehabilitative therapies of CBT, GET, and the non-rehabilitative, but therapist contact time matched, adaptive pacing therapy (APT), in which the patient was encouraged not to exceed limits imposed on their activity by their symptoms. The trial found that the rehabilitative therapies CBT and GET were more effective in both improving functioning and in reducing fatigue than SMC alone or SMC supplemented by non-rehabilitative APT. ${ }^{14}$ In other words, active rehabilitation was found to be more effective than non-rehabilitative approaches.

Those questioning the validity of these findings have disputed the case definition of the illness used to recruit participants to the trials and the use of patient-reported rather than objectively measured outcomes. They have pointed to patient group surveys which report that, outside the trial rehabilitation and GET in particular has made some patients worse. ${ }^{6}$, ${ }^{15-18}$ Responses to these methodological criticisms have been published . ${ }^{13,19-22}$ However, to help the reader better understand the controversy, we will briefly summarize some of the main criticisms and responses to them.

There are many published diagnostic criteria for CFS and for ME. ${ }^{2}$ Most of the published trials have used either the Oxford or the Centers for Disease Control (CDC) criteria. ${ }^{3,23}$ These definitions have been criticized as not capturing patients with the real illness of CFS/ME, by not requiring the symptom of post-exertional malaise. Whilst the generalizability of clinical trials to wider patient populations is an important issue, we find this argument unconvincing. Interestingly, none of the many case definitions of CFS or ME has been shown in a systematic review to be any more valid than any other. ${ }^{2}$ One study reported that the Oxford definition was so broad that it identified over $20 \%$ of the US population as having CFS (compared to two percent as defined by CDC criteria) but the study had misapplied the criteria. ${ }^{24,25}$ A systematic review of studies reported a median prevalence of $1.5 \%$ for Oxford defined CFS in the population or in primary care. ${ }^{2}$ In the context of the PACE trial, a sensitivity analysis found that the trial participants improved irrespective of the criteria. The London diagnostic criteria for ME require the patient to have post-exertional malaise. ${ }^{26}$ These patients improved to a similar degree to all those in the trial, with both GET and CBT. ${ }^{14}$ In light of this evidence, we suggest that the results of trials that used Oxford and other diagnostic criteria, which do not specifically require post-exertional malaise, are indeed generalizable to the wider population of patients with CFS/ME. Any reviews of the literature, which conclude there is insufficient evidence for rehabilitative therapies after excluding such trials, are therefore misleading. ${ }^{27}$

The use of patient-reported outcomes to judge effectiveness has been much debated as a source of bias. In the absence of any established objective test or 'biomarker' for CFS/ME, the condition is defined almost solely by patient report. ${ }^{1-3}$ It is therefore both appropriate and necessary to determine the outcome of treatment for CFS/ME by asking patients about the same symptoms and associated disability that were used to make the diagnosis, using standardised and validated patientreported outcome measures (PROMs). It is of course true that patient reports may suffer from bias in an unblinded trial if the patient felt more positively about a particular treatment. This issue was addressed in the PACE trial by measuring the expectations of participants about potential improvement, before they started their treatment. Whilst the lowest expectations of a therapy were for CBT, those who received it reported the greatest improvements. ${ }^{14}$ On the issue of blinding more broadly, a recent meta-epidemiological study of 142 Cochrane collaboration meta-analyses found no evidence that lack of blinding leads to exaggerated estimates of treatment effects in clinical trials. ${ }^{28}$

Some people have expressed concern that CBT and GET may cause harm to patients. This concern arises both from the common experience of patients and patient surveys that sudden increases in activity causes an increase should in symptoms. ${ }^{6}$ All trials be they medicinal or otherwise report on safety as well as benefits. In the PACE trial, six safety outcomes were examined and there was no evidence of harm found from the very gradual and collaboratively planned increases of activity used in CBT or GET. ${ }^{14,29}$ A more recent trial of guided self-help, based on GET, used the same six safety measures, and also found there were no significant differences in safety outcomes between this intervention and specialist medical care. ${ }^{30}$ It is of course likely that outside clinical trials, rehabilitative therapy is not always applied correctly; any medical intervention can cause harm if given at the wrong dose or frequency. In particular, rigidly applied programmes that are not collaborative or tailored to the patient's symptom 
severity and disability may lead to worsening of symptoms. ${ }^{31}$ The discrepancy between the reported findings of patient surveys and randomised controlled trials clearly merits further exploration. However, it seems likely that any harm reported from patient community surveys reflects poorly implemented therapy, as well as possible misdiagnosis of CFS/ME. ${ }^{31,32}$ In summary, the available trial evidence indicates that these therapies are safe, if given properly. ${ }^{33,34}$

One issue that is perhaps the most central to the debate about rehabilitation concerns the theoretical underpinning of such treatments. Rehabilitation, including CBT and GET, for CFS/ME assumes that disability and symptoms, once established, are at least in part maintained by factors that are reversible. The reversible factors include psychological and behavioural factors, such as the patients' worries about their symptoms and how they cope with them, as well as by associated physiological changes. ${ }^{35,36}$ A major concern of those who argue against rehabilitation is that such reversibility implies that the symptoms and disability of CFS/ME means CFS/ME is not a 'real physical illness'. ${ }^{6}$ Whilst this concern is understandable, the conclusion drawn is surely wrong. A degree of reversibility of an illness, demonstrated by successful rehabilitation, does not imply that the illness was not real. Notably in this regard, both CBT and GET have been found to be effective in improving the fatigue and disability accompanying many established medical conditions. ${ }^{37,38}$.

\section{ALTERNATIVES TO REHABILITATION}

If we abandon rehabilitation as a treatment, what are the alternatives? The only widely described and advocated alternative management approach is a form of 'pacing' in which patients are encouraged to stay within the 'energy envelope' imposed by the illness and not to attempt rehabilitation. ${ }^{6}$ However, the PACE trial found that such an approach was relatively ineffective in improving either patients' ability to do things or their symptoms and no better than specialist medical care alone. ${ }^{14,29}$ Furthermore, a systematic review of pharmacological interventions concluded 'that there is no clear recommended pharmaceutical therapy for CFS/ME. ${ }^{39}$ Given the lack of an effective alternative treatment to rehabilitation, we need to think twice before dismissing it as a treatment, given that trials continue to find that rehabilitative treatments are both safe and moderately effective for patients with CFS and related syndromes. ${ }^{40,41}$

\section{CONCLUSION}

In conclusion, the available research evidence from randomized trials supports the use of the rehabilitative therapies of CBT and GET for patients with CFS/ME. More research is of course needed into these approaches, as well as into other treatments for this neglected group of patients. However, it would be a disservice to our patients to tell them we have nothing to offer them when the evidence suggests that we have evidence-based therapies that are both safe and moderately effective for many.

Corresponding Author: Trudie Chalder, PhD, Department of Psychological Medicine, Institute of Psychiatry, Psychology \& Neuroscience, King's College London, 16, De Crespigny Park, London SE5 8AF, UK (e-mail: Trudie.chalder@kcl.ac.uk).

\section{Acknowledgements}

There was no specific funding for this article. TC acknowledges the financial support of the Department of Health via the National Institute for Health Research (NIHR) Specialist Biomedical Research Centre for Mental Health award to the South London and Maudsley NHS Foundation Trust (SLaM) and the Institute of Psychiatry at King's College London.

The views expressed in this article are those of the authors and not necessarily those of the NHS, the NIHR, or the Department of Health and Social Care.

\section{Declarations}

Conflict of Interest The authors were all members of the PACE trial research team. Trudie Chalder and Michael Sharpe have authored several books and book chapters on chronic fatigue syndrome and have received royalties for these. Peter White is an unpaid member of the Independent Medical Experts Group, which advises the UK Ministry of Defence regarding its Armed Forces Compensation scheme. He also provides paid consultancy to a re-insurance company. Trudie Chalder has conducted workshops on CBT for CFS and has received payment.

\section{References}

1. Institute of Medicine. Beyond myalgic encephalomyelitis/chronic fatigue syndrome: redefining an illness. Washington, D.C.: The National Academies Press; 2015.

2. Brurberg KG, Fønhus MS, Larun L, Flottorp S, Malterud K. Case definitions for chronic fatigue syndrome/myalgic encephalomyelitis (CFS/ME): a systematic review. BMJ Open. 2014;4:e003973

3. Reeves WC, Lloyd A, Vernon SD, Klimas N, Jason LA, Bleijenberg G, and the International Chronic Fatigue Syndrome Study Group. Identification of ambiguities in the 1994 chronic fatigue syndrome research case definition and recommendations for resolution. BMC Health Serv Res. 2003;3:1-9.

4. White PD. A perspective on causation of the chronic fatigue syndrome by considering its nosology. J Eval Clin Pract. 2019;25:991-6.

5. National Institute for Health and Clinical Excellence. Clinical guideline CG53. Chronic fatigue syndrome/myalgic encephalomyelitis (or encephalopathy): diagnosis and management. http://guidance.nice.org.uk/CG53 (accessed March 24, 2021).

6. Friedberg F, Sunnquist M, Nacul L. Rethinking the standard of care for myalgic encephalomyelitis/chronic fatigue syndrome. J Gen Intern Med. 2020;35:906-9.

7. Devasahayam A, Lawn T, Murphy M, White PD. Alternative diagnoses to chronic fatigue syndrome in referrals to a specialist service: a service evaluation survey. J Roy Soc Med Short Reports. 2012;3:4. 
8. Newton JL, Mabillard H, Scott A, Hoad A, Spickett G. The Newcastle NHS Chronic Fatigue Syndrome Service: not all fatigue is the same. J Roy Coll Phys Edin. 2010;40:304-7.

9. Malouff JM, Thorsteinsson EB, Rooke SE, Bhullar N, Schutte NS. Efficacy of cognitive behavioural therapy for chronic fatigue syndrome: a meta-analysis. Clin Psychol Rev. 2008;28:736-45.

10. Castell BD, Kazantzis N, Moss-Morris RE. Cognitive behavioural therapy and graded exercise for chronic fatigue syndrome: a metaanalysis. Clin Psychol Sci Pract. 2011;18:311-24.

11. Marques MM, De Gucht V, Gouveia MJ, Leal I, Maes S. Differential effects of behavioural interventions with a graded physical activity component in patients suffering from Chronic Fatigue (Syndrome): An updated systematic review and meta-analysis. Clinical Psychol Rev. 2015;40:123-37.

12. Larun L, Brurberg KG, Odgaard-Jensen J, Price JR. Exercise therapy for chronic fatigue syndrome. Cochrane Database Sys Rev. 2019;4:CD003200.

13. White PD, Chalder T, Sharpe M. PACE trial manuals. Available at: https://www.qmul.ac.uk/wolfson/research-projects/currentprojects/projects/pace-trial.html. Last accessed July 17th, 2020.

14. White PD, Goldsmith KA, Johnson AL, Potts L, Walwyn R, DeCesare JC, Baber HL, Burgess M, Clark LV, Cox DL, Bavinton J, Angus BJ, Murphy G, Murphy M, O’Dowd H, Wilks D, McCrone $\mathrm{P}$, Chalder T, Sharpe M, on behalf of the PACE trial management group. Comparison of adaptive pacing therapy, cognitive behaviour therapy, graded exercise therapy, and specialist medical care for chronic fatigue syndrome (PACE): a randomised trial. Lancet. 2011;377:823-36.

15. Geraghty KJ. PACE-Gate: When clinical trial evidence meets open data access. J Health Psychol. 2016;22:1106-12.

16. Wilshire C, Kindlon T, Matthees A, McGrath S. Can patients with chronic fatigue syndrome really recover after graded exercise or cognitive behavioral therapy? A critical commentary and preliminary re-analysis of the PACE trial. Fatig Biomed Health Behav. 2017;5:43-56.

17. Mitchell AJ. Controversy over exercise therapy for chronic fatigue syndrome: Key lessons for clinicians and academics: Commentary on... Cochrane Corner. BJPsych Adv. 2017;23:145-8.

18. Wilshire CE, Kindlon T, Courtney R, Matthees A, Tuller D, Geraghty K, Levin B. Rethinking the treatment of chronic fatigue syndrome-a reanalysis and evaluation of findings from a recent major trial of graded exercise and CBT. BMC Psychol. 2018;6:6.

19. White PD, Chalder T, Sharpe M, Angus BJ5, Baber HL, Bavinton J, Burgess M, Clark LV, Cox DL, DeCesare JC, Goldsmith KA, Johnson AL, McCrone P, Murphy G, Murphy M, O’Dowd H, Potts L, Walwyn R, Wilks D. Response to the editorial by Dr Geraghty. J Health Psychol. 2017;22:1113-7.

20. Sharpe M, Chalder T, Johnson AL, Goldsmith KA, White PD. Do more people recover from chronic fatigue syndrome with cognitive behaviour therapy or graded exercise therapy than with other treatments? Fatig Biomed Health Behav. 2017;5:57-61.

21. Chalder T, White PD, Sharpe M, Mitchell AJ. Controversy over exercise therapy for chronic fatigue syndrome: continuing the debate. BJPsych Advances. 2017;23:288-91.

22. Sharpe M, Goldsmith K, Chalder T. The PACE trial of treatments for chronic fatigue syndrome: a response to WILSHIRE et al. BMC Psychol. 2019;7:15.

23. Sharpe MC, Archard LC, Banatvala JE, Borysiewicz LK, Clare AW, David A, Edwards RHT, Hawton KEH, Lambert HP, Lane RJM, McDonald EM, Mowbray JF, Pearson DJ, Peto TEA, Preedy VR, Smith AP, Smith DG, Taylor DJ, Tyrrell DAJ, Wessely S, White PD, Behan PO, Clifford Rose F, Peters TJ, Wallace PG, Warrell DA, Wright DJM. A report - chronic fatigue syndrome: guidelines for research. J Roy Soc Med. 1991:84;118-21.

24. Baraniuk JN. Chronic Fatigue Syndrome prevalence is grossly overestimated using Oxford criteria compared to Centers for Disease Control (Fukuda) criteria in a U.S. population study. Fatigue. 2017; 5:215-230. doi:https://doi.org/10.1080/21641846.2017.1353578

25. Wessely S, Sharpe M. Letter to the Editor. Fat Biomed Health Behav. 2018;6:61-62, https://doi.org/10.1080/21641846.2017. 1364148

26 The London criteria. Given in the Report on chronic fatigue syndrome (CFS), post viral fatigue syndrome (PVFS) and myalgic encephalomyelitis (ME). Westcare, Bristol: The National Task Force, 1994.

27. Agency for Healthcare Research and Quality. Diagnosis and Treatment of Myalgic Encephalomyelitis/Chronic Fatigue Syndrome. 2016. https://effectivehealthcare.ahrq.gov/products/chronicfatigue/research. (Last accessed March 24, 2021).

28. Moustgaard H, Clayton GL, Jones HE, Boutron I, Jørgensen L, Laursen DL, Olsen MF, Paludan-Müller A, Ravaud P, Savović J, Sterne JA. Impact of blinding on estimated treatment effects in randomised clinical trials: meta-epidemiological study. BMJ. 2020;368:16802.

29. Dougall D, Johnson A, Goldsmith K, Sharpe M, Angus B, Chalder T, White P. . Adverse events and deterioration reported by participants in the PACE trial of therapies for chronic fatigue syndrome. J Psychosom Res. 2014;77:20-26. DOI: https://doi. org/10.1016/j.jpsychores.2014.04.002.

30. Clark LV, Pesola F, Thomas JM, Vergara-Williamson M, Beynon M, White PD. Graded exercise therapy guided self help versus specialist medical care for chronic fatigue syndrome (GETSET): a randomised controlled trial. Lancet. 2017;390:363-73.

31. Gladwell PW, Pheby D, Rodriguez T, Poland F. Use of an online survey to explore positive and negative outcomes of rehabilitation for people with CFS/ME. Disabil Rehab. 2014;36:387-94.

32. Brimmer DJ, Maloney E, Devlin R, Jones JF, Boneva R, Nagler C, LeRoy L, Royal S, Tian H, Lin JM, Kasten J. A pilot registry of unexplained fatiguing illnesses and chronic fatigue syndrome. BMC Res Notes. 2013;6:309.

33. Montgomery J. The PACE trial and the Committee's inquiry on Research Integrity. 2019. Available on: https://www.parliament. uk/documents/commons-committees/science-technology/Corre spondence/190129-Sir-Jonathan-Montgomery-Health-Resea rch-Authority-to-Chair-re-PACE-trial.pdf. Last accessed July 17, 2020.

34. Hawkes N. PACE chronic fatigue trial was properly conducted, says UK research watchdog. BMJ (Online). 2019 Feb 7;364.

35. Chalder T, Goldsmith KA, White PD, Sharpe M, Pickles AR. Rehabilitative therapies for chronic fatigue syndrome: a secondary mediation analysis of the PACE trial. Lancet Psychiatry. 2015;2:141-52.

36. Wearden AJ, Emsley R. Mediators of the effects on fatigue of pragmatic rehabilitation for chronic fatigue syndrome. J Consult Clin Psychol. 2013;81:831-8.

37. Mustian KM, Alfano CM, Heckler C, Kleckner AS, Kleckner IR, Leach CR, Mohr D, Palesh OG, Peppone LJ, Piper BF, Scarpato J, Smith T, Sprod LK, Miller SM. Comparison of pharmaceutical, psychological, and exercise treatments for cancer-related fatigue: A meta-analysis. JAMA Oncol. 2017;3:961-968. https://doi.org/ 10.1001/jamaoncol.2016.6914

38. Moss-Morris R, Harrison AM, Safari R, Norton S, van der Linden ML, Picariello F, Thomas S, White C, Mercer, T. Which behavioural and exercise interventions targeting fatigue show the most promise in multiple sclerosis? A systematic review with narrative synthesis and meta-analysis. Behav Res Ther. 2019;28:103464.

39. Collatz A, Samantha C. Johnston SC, Staines DR, MarshallGradisnik SM. A systematic review of drug therapies for chronic fatigue syndrome/myalgic encephalomyelitis. Clinic Therap. 2016;38:1263 - 1271.e9. https://doi.org/10.1016/j.clinthera. 2016.04.038

40. Keijmel SP, Delsing CE, Bleijenberg G, van der Meer JW, Donders RT, Leclercq M, Kampschreur LM, van den Berg M, Sprong T, Nabuurs-Franssen MH, Knoop H. . Effectiveness of longterm doxycycline treatment and cognitive-behavioral therapy on fatigue severity in patients with $Q$ fever fatigue syndrome (Qure study): a randomized controlled trial. Clin Infect Dis. 2017;64:998-1005.

41. Janse A, Worm-Smeitink M, Bleijenberg G, Donders R, Knoop H. Efficacy of web-based cognitive-behavioral therapy for chronic fatigue syndrome: randomised controlled trial. $\mathrm{Br} \mathrm{J}$ Psychiatry. 2018;212:112-8.

Publisher's Note Springer Nature remains neutral with regard to jurisdictional claims in published maps and institutional affiliations. 